\title{
Micro-X-Ray Fluorescence and the Old Masters
}

\section{Non-destructive in situ characterisation of the varnish of historical Low Countries stringed musical instruments}

\author{
Francesco Caruso • Steven Saverwyns • Marina Van Bos • \\ Delia Francesca Chillura Martino • Anne-Emmanuelle Ceulemans • Joris de Valck • \\ Eugenio Caponetti
}

Received: 28 July 2011 / Accepted: 14 December 2011 / Published online: 31 December 2011

(C) Springer-Verlag 2011

\begin{abstract}
In recent years, a growing attention has been addressed to the study of the varnish from early musical instruments. The surfaces of nine historical Low Countries stringed musical instruments from the collection of the "Musical Instruments Museum" in Brussels were nondestructively analysed by in situ micro-X-Ray Fluorescence spectroscopy in dispersive mode. It was found that the main pigments dispersed in the varnish were iron- and manganese-based earths. The presence of a chromium-based pigment in one of the analysed instruments makes it appreciably different from the others. Other findings were discussed and compared with previously published results. The collection of such information plays a relevant role in the recovery of the applied formulations that is an interesting issue for conservators, luthiers and art historians.
\end{abstract}

F. Caruso $(\bowtie)$ · D.F. Chillura Martino · E. Caponetti Dipartimento di Chimica "Stanislao Cannizzaro", Università degli Studi di Palermo, Viale delle Scienze ed. 17-Parco d'Orleans II, 90128 Palermo, Italy

e-mail: fcaruso@ifb.baug.ethz.ch

F. Caruso $\cdot$ S. Saverwyns $\cdot$ M. Van Bos

Royal Institute for Cultural Heritage (KIK-IRPA), Parc

du Cinquantenaire 1, 1000 Brussels, Belgium

A.-E. Ceulemans · J. de Valck

Musical Instruments Museum, Hofberg 2 Montagne de la Cour, 1000 Brussels, Belgium

Present address:

F. Caruso

Institut für Baustoffe (IfB), ETH Zürich, Schafmattstrasse 6,

HIF B 60.2, 8093 Zurich, Switzerland

\section{Introduction}

The varnishing of a stringed musical instrument constitutes an important step of its finishing because of the functional (fixation of the pigments to the substrate), protective (high resistance to physico-chemical and mechanical agents) and aesthetic (good transparency and brightness and lightness of the colours) roles of the varnish $[1,2]$.

Although being complex mixtures of organic and inorganic materials, the varnishes of musical instruments are usually distinguished on the basis of the solvent ${ }^{1}$ used: (a) spirit-based; (b) siccative oil-based; (c) essential oilbased. Considerable scientific efforts have been made to identify the organic and the inorganic portions of the surface layers of several historical stringed instruments. The inorganic portion has been studied by several destructive, micro-destructive and non-destructive (ND) techniques [3].

An ND energy dispersive X-Ray Fluorescence (EDXRF) study was conducted on 15 North-Italian instruments dated from the 16th to the 18th century from the collection of the "Musée de la Musique" in Paris [4]. The author found the presence of lead, arsenic and mercury. Lead-based compounds were likely referable to the use of an oil-based varnish, whereas arsenic- and mercury-based compounds were used as pigments.

Von Bohlen and Meyer carried out the total-reflection XRF characterisation of micro-samples from North-Italian, Austrian, English and French instruments dated from the 16th to the 20th century [5, 6]. They found that iron, arsenic and lead are in a higher relative quantity in the samples from historical instruments (16-18th century ones), whereas man-

\footnotetext{
${ }^{1}$ In fact, the most abundant component since some substances often remain in suspension.
} 
Table 1 Instrument, number of inventory, transcription of the inner label and number of sampled areas of the studied musical instruments of the "Musical Instruments Museum" in Brussels (Belgium)

\begin{tabular}{|c|c|c|}
\hline $\begin{array}{l}\text { Instrument and } \\
\text { no. of inventory }\end{array}$ & Transcription of the inner label & No. of areas analysed \\
\hline Violin 1338 & $\begin{array}{l}\text { Printed: "Benoit-Joseph Boussu, me/Luthier à Bruxelles 1750". The last two digits of the label } \\
\text { are handwritten }\end{array}$ & 32 \\
\hline Cello 1372 & Handwritten: "Benoit Joseph Boussu ME/luthier A Bruxelles 1757" & 23 \\
\hline Cello 1374 & $\begin{array}{l}\text { Printed: "Gaspar Borbon/tot Brussel 1688". The last two digits of the label are handwritten and } \\
\text { somewhat uncertain }\end{array}$ & 49 \\
\hline Kit 2764 & Handwritten: "Gaspar Borbon tot Brussel 1686" & 7 \\
\hline Violin 2774 & Printed: "GASPAR BORBON/tot Brussel 16..." & 17 \\
\hline Violin 2781 & Handwritten: "Boussu, a/... 1750" & 18 \\
\hline Violin 2782 & Handwritten: "B. I. Boussu, a Etterbeecke/près de Bruxelles, Le/20 8bre 1752 n 36" & 22 \\
\hline Violin 2784 & $\begin{array}{l}\text { Printed: "Benoit Joseph BOUSSU,/Maitre Luthier à Bruxel-/les 1753". The last digit of the } \\
\text { label is handwritten }\end{array}$ & 25 \\
\hline Violin 2836 & Printed: "Gaspar Borbon tot Brusselles 1692" & 21 \\
\hline
\end{tabular}

ganese, copper, cobalt, zinc and lead are more present in the varnishes of recent instruments (20th century ones).

To date, the scientific interest has been mainly focused on North-Italian instruments. Therefore, there is an overall lack of knowledge for instruments from other regions, including the ones from the Low Countries [3].

The aim of the present study is the ND elemental characterisation of the varnish from a selection of Low Countries historical stringed instruments from the "Musical Instruments Museum" in Brussels (Belgium) to fill the missing knowledge on such instruments, obtain information about their varnishes and possible conservation/restoration treatments previously executed and not documented.

\section{Analysed musical instruments}

The nine analysed instruments were chosen by the conservators of the "Musical Instruments Museum" because, among others, they presented issues in the authentication, the state of preservation and peculiarity of their manufacture.

They are among the finest instruments of the "Musical Instruments Museum": five by Gaspar Borbon and four by Benoit-Joseph Boussu. No information exists as to possible restorations made on these instruments, either before or after their arrival at the museum.

The instrument, the number of inventory, the transcription of the inner labels and the number of areas analysed are reported in Table 1.

Gaspar (or Jaspar) Borbon (born in 1632 or 1635, active from 1664 to 1702 and died in 1710 [7, 8]) was a member of a renowned family of musicians and luthiers that worked for the Brussels Court Chapel.
Borbon's instruments are good examples of the so-called archaic manufacturing method that was commonly used in the Low Countries until the 18th century. They were built without a mould [9], the sides being inserted into groves carved in the back of the instruments. Many archaic violins, violas and cellos were modernised in the course of time, but this peculiar building method is still easily visible on instruments 1374 and 2836. Viola 2836 is even more exceptional as it is entirely kept in its original state, with a baroque neck and fingerboard.

Benoit-Joseph Boussu was a luthier active from 1747 to 1760 in Brussels. Pretty little is known about his life. His instruments were possibly built in the classical way on moulds, frequently employing yellow varnishes and are based on the model by Nicolò Amati [10]. They are qualitatively comparable to the finest North-Italian ones.

Only one of Boussu's analysed instruments shows a baroque neck (violin 2781).

No documentation is available about possible conservation treatments carried out on the instruments. In fact, conservation reports on six of the nine studied instruments (violins 1338, 2774, 2781, 2782, 2836 and cello 1372) exists only after the beginning of the 1980s. Nevertheless, they are about some delicate conservative actions (e.g. soaping of the pegs, gluing of detached parts, etc.) and not concerning the varnish.

The analysed areas were selected to have good statistical information and on the basis of the presence of interesting points (evidenced during the prior observation under visible and UV light).

A picture of one of the analysed instrument is shown in Fig. 1. 
Fig. 1 The cello 1374

attributed to G. Borbon

photographed under visible (a)

and UV (b) light. Picture used

by permission of the "Musical

Instruments Museum", Brussels

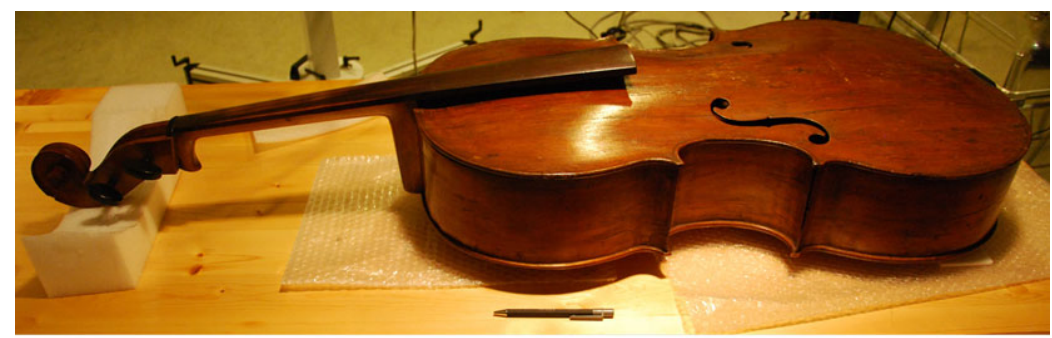

a

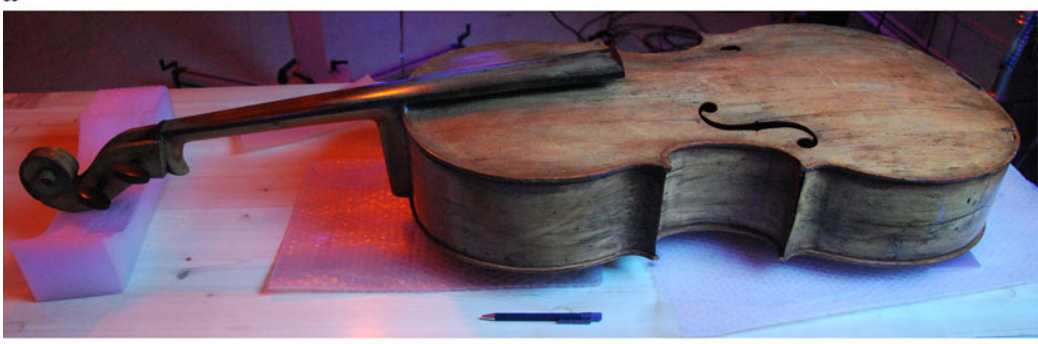

b

\section{Instrumental conditions}

The instrument used was an ARTAX $\mu$-XRF portable instrument by Bruker (Bruker Belgium S.A./N.V., Brussels, Belgium). It includes an air-cooled metal ceramic $\mathrm{X}$-ray tube with a tungsten target. The applied acceleration potential and current were $50 \mathrm{kV}$ and $600 \mu \mathrm{A}$, respectively. Under these conditions, the instrument allows the detection of elements with an atomic number higher than 14 (silicon). The unfiltered radiation was collimated to $200 \mu \mathrm{m}$. The silicon drift detector (SDD) was cooled at a temperature of $-15{ }^{\circ} \mathrm{C}$ by a Peltier element. The SDD has an area of $10 \mathrm{~mm}^{2}$ and allows a resolution of less than $155 \mathrm{eV}$ at $10 \mathrm{kcps}$. Measurements were carried out in air and the collection time was $200 \mathrm{~s}$. The head of the instrument was mounted on a tripod and connected to a Windows PC. The data collecting and analysing software was the ARTAX package by Bruker. Emission peaks were best fitted with Gaussian functions, and their areas were computed after the subtraction of the background.

\section{Results and discussion}

Potassium and calcium were detected in every analysed area of every instrument. These elements, along with sulphur and chlorine (also often found), can be attributed to the secretion of human sweat [4] or to the inorganic portion of the wood below the varnish. In fact, potassium and calcium are the most abundant inorganic elements for spruce, beech and bark [11, 12].

The occurrence of the other detected elements on the surface of the analysed musical instruments is shown in Table 2.

Iron, manganese, titanium, lead and zinc were found on the surface of every musical instrument. Copper and strontium were found on the surface of five and four instruments,
Table 2 Occurrence of the detected elements on the surface of the analysed musical instruments of the "Musical Instruments Museum" in Brussels (Belgium). The number indicates the percentage of the sampled spots in which an element was found

\begin{tabular}{lrrrrrrrrr}
\hline Element & 1338 & 1372 & 1374 & 2764 & 2774 & 2781 & 2782 & 2784 & 2836 \\
\hline $\mathrm{Fe}$ & 100 & 100 & 100 & 100 & 100 & 100 & 100 & 100 & 100 \\
$\mathrm{Mn}$ & 87 & 91 & 33 & 100 & 94 & 94 & 100 & 84 & 71 \\
$\mathrm{Ti}$ & 3 & 9 & 57 & 14 & 24 & 22 & 32 & 24 & 48 \\
$\mathrm{~Pb}$ & 9 & 9 & 82 & 29 & 41 & 17 & 36 & 32 & 38 \\
$\mathrm{Zn}$ & 19 & 9 & 49 & 86 & 35 & 39 & 68 & 20 & 57 \\
$\mathrm{Cu}$ & 0 & 0 & 4 & 0 & 12 & 0 & 9 & 8 & 19 \\
$\mathrm{Sr}$ & 0 & 0 & 2 & 0 & 0 & 11 & 5 & 0 & 5 \\
\hline
\end{tabular}

respectively. Iron combined with manganese is an indication for earth pigments like siennas and umbers giving a range of yellow-red-brown tints [13-15].

The presence of titanium can be attributed to impurities of the iron-based pigments [14].

Lead-based compounds (such as massicot, $\mathrm{PbO}$, lead white, $2 \mathrm{PbCO}_{3} \cdot \mathrm{Pb}(\mathrm{OH})_{2}$, and red lead, $2 \mathrm{PbO} \cdot \mathrm{PbO}_{2}$ ) were often added as pigments and to accelerate and uniform the desiccation of an oil-based varnish [4-6, 13]. Its presence can be regarded as an indicator (although not the only one [3]) for the use of an oil based-varnish [5, 13]. Furthermore, the values of the areas of the lead peaks are correlated with the areas of iron ones $\left(r_{\mathrm{FePb}}\right.$, the Pearson index of correlation, ${ }^{2}$ is more than 0.5 for every instrument and up to

${ }^{2}$ Pearson correlation coefficient is a rescaled covariance:

$r_{X Y}=\frac{s_{X Y}}{s_{X} s_{Y}}$

where $s_{X Y}$ is the sample covariance and $s_{X}$ and $s_{Y}$ are sample standard deviations [16]. 
0.95 in the case of instrument 2781) meaning that lead was likely added to the original recipe.

The presence of zinc can be attributed to either the secretion of human sweat [4] or some residual polish impurities [17]. Its detection was not easy because of the interference with the L lines of the tungsten target [14].

Chromium was found in the $98 \%$ of the analysed spots on the varnish of the cello 1374. To the best of our knowledge, this is the first time that a chromium pigment is found in the varnish of a historical musical instrument.

A typical spectrum recorded on the surface of the cello 1374 is reported in Fig. 2.

The occurrence of chromium on the whole surface of the instrument, its relative high content (mean value of the chromium peak area $=1317 \mathrm{keV}$ counts) and a very low correlation $\left(r_{\mathrm{FeCr}}=0.25\right)$ between the values of the areas of the chromium peaks and the iron ones exclude the pos-

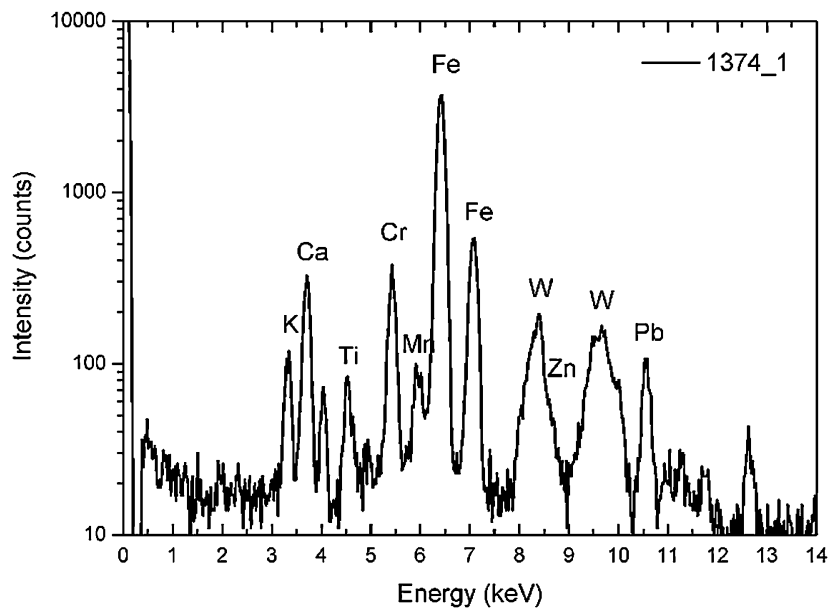

Fig. 2 XRF spectrum of the first sampled spot on the surface of the cello 1374 attributed to G. Borbon. Tungsten peaks are attributable to the target of the instrument. A logarithmic scale is used on the axis of intensity for sake of clarity sibility that such an element is an impurity of iron-based pigments [14]. Analogue considerations can be drawn out about the low correlation between the values of the areas of the chromium peaks and the lead ones $\left(r_{\mathrm{PbCr}}=0.42\right)$, thus excluding the possibility of the use of chrome orange (basic lead chromate).

Two reasonable hypotheses would explain the presence of a chromium-based pigment in cello 1374: (i) the luthier used an uncommon (and/or used for other purposes) pigment, such as chromite $[18,19]$ for colouring the varnish; (ii) the instrument was re-varnished, at the earliest in the beginning of the 19th century.

To further support the above-mentioned hypotheses, the average $\mathrm{Fe} / \mathrm{Mn}$ ratio was computed for every instrument. Deviant values were rejected, on the basis of a twotailed $Q$ test, at the $95 \%$ confidence level, accordingly to Rorabacher [20]. The deviant values often corresponded to regions in which droplets of varnishes, carved parts and other surface imperfections were noticeable. The values are reported as histograms with the corresponding standard deviation bars in Fig. 3. This manipulation of the data confirms the above-mentioned peculiarity of such musical instruments.

A particularly interesting spot on the surface of the violin 2781 by B.-J. Boussu is on the bottom right part of the top. The surface of the instrument is slightly carved in that region. This is well evidenced when illuminated under UV light in Fig. 4.

The spectrum of this region is reported in Fig. 5.

The simultaneous presence of barium and cadmium is likely referable to the use of a cadmium yellow lithopone. This is an artificial mixture of cadmium sulphide (CdS) and barium sulphate $\left(\mathrm{BaSO}_{4}\right)$ having heat and light resistance properties. It was introduced in 1927 [13, 15]. As a consequence, this region could have been retouched with such a pigment after the acquisition of the cello by the "Musical Instruments Museum”.
Fig. 3 Average $\mathrm{Fe} / \mathrm{Mn}$ ratio for every musical instrument. Values corresponding to cello 1374 and violin 2836 considerably deviate from the ones computed for other instruments, somehow corroborating their peculiarity

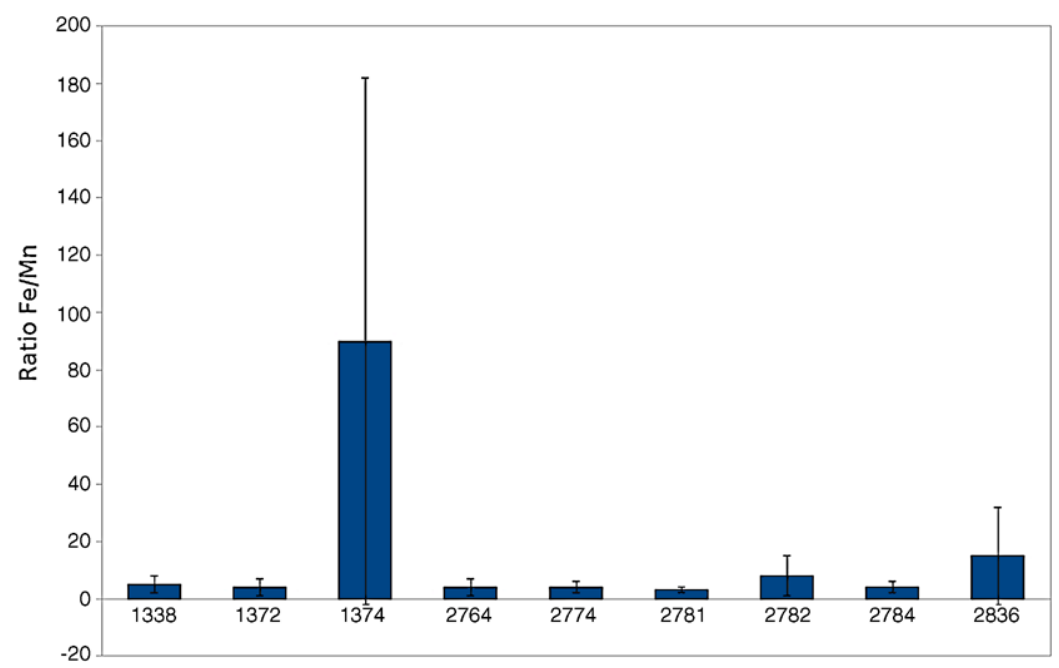


Fig. 4 Bottom right part of the top of the violin 2781 by B.-J. Boussu illuminated by UV light. For the sake of clarity, the zone of interest has been highlighted. This was obtained by adding a brightness/contrast mask (brightness $=100 \%$, contrast $=$ $100 \%$ ) to the original picture with Adobe Photoshop CS5

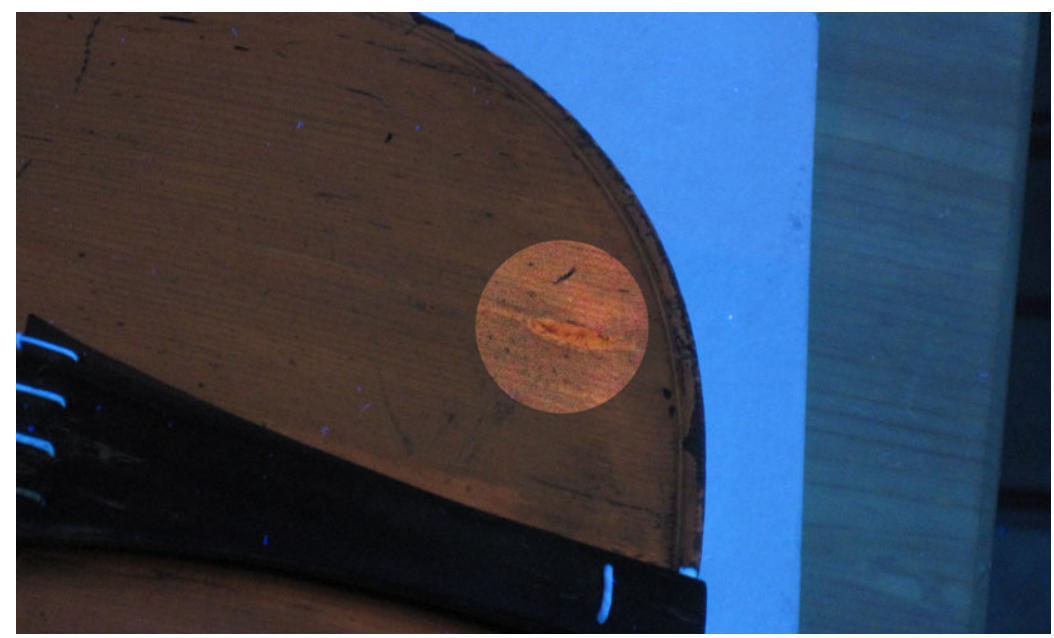

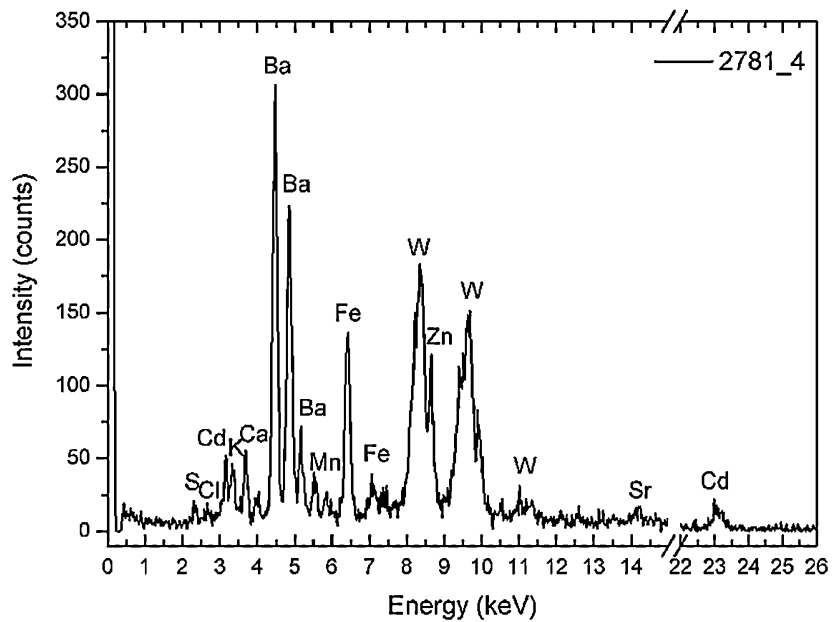

Fig. 5 XRF spectrum of the bottom right part of the top of the cello 2781 by B.-J. Boussu. Tungsten peaks are attributable to the target of the instrument

Mercury-based (such as mercury sulfide, i.e. cinnabar or vermilion [4]) and tin-based pigments (such as lead-tin yellow) were not found. A weak signal attributable to arsenic was detected only in one spot of the cello 1374 .

The results here shown differ somewhat from the ones reported in other publications (mainly on North-Italian instruments) because of the absence of arsenic- and mercurybased pigments $[3,4,21]$. Conversely, a study on five Stradivari's instruments reports the presence of pure ochre (instead of an earth) pigment in three of them [21], resembling the results here reported. The possibility of microsampling such instruments and carrying out destructive elemental (e.g. by an Inductively Coupled Plasma technique) and organic (e.g. by chromatographic techniques) analyses could be very useful to assess both the presence of other light element-based materials (such as potash alum [21] or borate [22]) and the exact composition of the organic part of the varnish.

\section{Conclusions}

Nine historical Low Countries stringed musical instruments from the collection of the "Musical Instruments Museum" in Brussels (Belgium) were studied by ND in situ $\mu$-XRF to shed some light on the inorganic materials employed for the manufacture of valuable instruments in the Low Countries from the 17th to the 18th century and to obtain information about previous conservation/restoration treatments and retouches.

On the basis of the above-discussed results, it was found that the inorganic material added in the varnish of eight of the nine instruments here studied is similar, mainly consisting of an iron- and manganese-based earth. Lead-based compounds were found in every instrument indicating the probable use of a siccative oil as main organic medium for the varnish.

The probable presence of cadmium yellow lithopone on a spot of the surface of the violin 2781 by B.-J. Boussu indicates a probable local non-documented retouch made, at the earliest, at the end of the 1920s.

In the case of the cello 1374, it was found that this was one of the peculiar instruments made by G. Borbon or the instrument was revarnished after its original manufacture. This is the first time that a chromium-based pigment is found in a varnish of a historical stringed musical instrument.

Finally, the results of this work will help conservators and organologists to better understand the varnishing techniques and the materials used by the luthiers in this European region and propose scientific explanations to the secrets of the Old Masters.

Acknowledgements The authors wish to thank Paolo Oliveri for his helpful comments to improve the manuscript and Fulvio Caruso for his help in editing Fig. 4. Francesco Caruso acknowledges an Erasmus LLP Placement grant allowing him to spend a three months and a half internship at the KIK-IRPA. 


\section{References}

1. V. Massa, G. Scicolone, Le Vernici per il Restauro-I Leganti, 3rd edn. (Nardini, Firenze, 1998)

2. G. Tavlaridis, Technology of materials employed for the construction of bowed musical instruments, in Il Restauro Conservativo del Contrabbasso Panormo, ed. by Centro Regionale per la Progettazione e il Restauro. Regione Siciliana. Assessorato dei Beni Culturali, Ambientali e della Pubblica Istruzione (Dipartimento dei Beni Culturali, Ambientali e dell'Educazione Permanente, Palermo, 2008), pp. 170-173

3. J.-P. Echard, B. Lavédrine, Review on the characterization of ancient stringed musical instrument varnishes and implementation of an analytical strategy. J. Cult. Heritage 9, 420-429 (2008)

4. J.-P. Echard, In situ multi-element analyses by energy-dispersive $\mathrm{X}$-ray fluorescence on varnishes of historical violins. Spectrochim. Acta, Part B, At. Spectrosc. 59, 1663-1667 (2004)

5. A. Von Bohlen, F. Meyer, Microanalysis of old violin varnishes by total-reflection X-ray fluorescence. Spectrochim. Acta, Part B, At. Spectrosc. 52, 1053-1056 (1997)

6. A. Von Bohlen, Total reflection X-ray fluorescence spectrometry-A versatile tool for ultra-micro analysis of objects of cultural heritage. e-PS 1, 23-34 (2004)

7. M. Haine, N. Meeùs, Dictionnaire des facteurs d'instruments de musique en Wallonie et à Bruxelles du 9e siécle à nos jours (P. Mardaga, Bruxelles, 1986)

8. M. Haine, N. Meeùs, Instruments de Musique anciens à Bruxelles et en Wallonie-17e-20e siécles (P. Mardaga, Bruxelles, 1986)

9. K. Moens, La "nascita" del violino nei Paesi Bassi del sud: alla ricerca di un luogo dove collocare l'inizio della storia del violino, in Monteverdi, imperatore della musica (1567-1643), ed. by M. Tiella (Accademia roveretana di musica antica-Istituto per la ricerca organologica ed il restauro, Rovereto, 1993), pp. 84-131

10. C. Stainer, A Dictionary of Violin Makers (Novello, London, 1896)

11. S.C. van Lith, V. Alonso-Ramirez, P.A. Jensen, F.J. Frandsen, P. Glarborg, Release to the gas phase of inorganic elements during wood combustion. Part 1: development and evaluation of quantification methods. Energy Fuels 20, 964-978 (2006)

12. S.C. van Lith, P.A. Jensen, F.J. Frandsen, P. Glarborg, Release to the gas phase of inorganic elements during wood combustion. Part 2: influence of fuel composition. Energy Fuels 22, 1598-1609 (2008)

13. M. Matteini, A. Moles, La Chimica nel Restauro-I Materiali dell'Arte Pittorica (Nardini, Firenze, 2004)

14. C. Seccaroni, P. Moioli, Fluorescenza X-Prontuario per l'Analisi XRF Portatile Applicata a Superfici Policrome (Nardini, Firenze, 2004)

15. A. Casoli, M.P. Colombini, M. Matteini, La chimica dei materiali pittorici, in Chimica per l'Arte, ed. by L. Campanella (Zanichelli, Bologna, 2007)

16. J.L. Rodgers, W.A. Nicewander, Thirteen ways to look at the correlation coefficient. Am. Stat. 42, 59-66 (1988)

17. A. von Bohlen, S. Röhrs, J. Salomon, Spatially resolved element analysis of historical violin varnishes by use of $\mu$ PIXE. Anal. Bioanal. Chem. 387, 781-790 (2007)

18. E. Ozel, S. Tura, Production and characterisation of ironchromium pigments and their interaction with transparent glazes. J. Eur. Ceram. Soc. 23, 2097-2104 (2003)

19. N.C.F. Groot, J. Dik, G. Van der Kooij, P.F.A. Alkemade, V.G.M. Sivel, F.D. Tichelaar, Dark and shiny: the discovery of chromite in bronze age faience. Archaeometry 48, 229-236 (2006)

20. D.B. Rorabacher, Statistical treatment for rejection of deviant values: critical values of Dixon's " $Q$ " parameter and related subrange ratios at the $95 \%$ confidence level. Anal. Chem. 63, 139-146 (1991)

21. J.-P. Echard, L. Bertrand, A. von Bohlen, A.-S. Le Hô, C. Paris, L. Bellot-Gurlet, B. Soulier, A. Lattuati-Derieux, S. Thao, L. Robinet, B. Lavédrine, S. Vaiedelich, The nature of the extraordinary finish of Stradivari's instruments. Angew. Chem., Int. Ed. Engl. 49, 197-201 (2010)

22. J. Nagyvary, R.N. Guillemette, C.H. Spiegelman, Mineral preservatives in the wood of Stradivari and Guarneri. PLoS ONE 4, e4245 (2009) 